San Jose State University

From the SelectedWorks of Marie Haverfield

2014

\title{
A theme analysis of experiences reported by adult children of alcoholics in online support forums
}

Marie C. Haverfield, Rutgers University

Jennifer A. Theiss, Rutgers University 
A Theme Analysis of Experiences Reported by Adult Children of Alcoholics in Online Support Forums

\author{
Marie C. Haverfield \\ Jennifer A. Theiss \\ Rutgers University
}

Author Note

Marie C. Haverfield is a doctoral candidate in the Department of Communication at Rutgers University where Jennifer A. Theiss (Ph.D., University of Wisconsin) is an Associate Professor. Address correspondence to Marie C. Haverfield, 4 Huntington Street, New Brunswick, NJ. 08901, 408-375-6966, marie.haverfield@ rutgers.edu. The authors wish to thank John Leustek, Corrine Pusillo, and Charles Tong for their assistance with the analysis. 


\begin{abstract}
Growing up with an alcoholic parent can have a lasting effect on children and contribute to a variety of challenging outcomes in adulthood. This study identified the various experiences that adult children of alcoholics discuss with their peers in online support groups. Trained coders conducted a thematic analysis of 504 message board posts collected over a period of 60 days from three different online support groups to identify issues that children of alcoholics face in adulthood. Seven themes emerged from the analysis: a) empowerment through support, b) interference of parent in adulthood, c) connection to inner child and need to re-parent, d) low self-esteem and insecurity, e) anger and resentment, f) romantic relationship problems, and g) problems communicating. The results of this study provide insight into the issues that adult children of alcoholics need to address as part of their own recovery and suggest avenues of exploration for practitioners who work with high risk families.
\end{abstract}




\section{A Theme Analysis of Experiences Reported by Adult Children of Alcoholics in Online Support Forums}

There are roughly 26.8 million children of alcoholics (CoA) in the United States (ADP, 2007). Adult children of alcoholics (ACoA) often struggle to communicate effectively with relationship partners and find it difficult to develop healthy intimate relationships (Beesley \& Stoltenberg, 2002; Dayton, 2009; Drejer, Theikjaard, Teasedale, Schulsinger, \& Goodwin, 1985). The psychological problems that ACoA experience are linked to depression, anxiety, low self-esteem, and hypervigilence of others (Diaz et al., 2008; Dayton, 2009). One challenge to understanding the experiences of ACoA is that many individuals are reluctant to disclose information about this aspect of their family due to the stigma associated with alcoholism (Hall \& Webster, 2007), which may prevent ACoA from properly coping with issues stemming from the disease (Hall \& Webster, 2007). Online support groups provide an anonymous forum for people to discuss experiences, communicate hardship, seek support, and commiserate with people who share similar life experiences (c.f., Walther \& Boyd, 2002). Therefore, we turn to online support communities for ACoA as a forum for observing reports of the experiences and outcomes of having an alcoholic parent. Identifying the issues that ACoA continue to deal with in adulthood can assist in shaping programs and interventions to help CoA cope with their family circumstances and manage their expectations for the long-term implications of having an alcoholic parent.

\section{The Impact of Alcoholism on the Family}

Alcoholism is often referred to as a family disease because all members of the family living with the alcoholic are affected (Ackerman, 1986). Alcoholics tend to prioritize alcohol over family, neglect family and work obligations, experience financial distress, become verbally 
and physically abusive, and withdraw from loved ones (Schade, 2006). Common characteristics of alcoholics include low frustration tolerance, desire for perfection, anxiety, poor self-image, and a sense of loneliness (NIAAA, 2010). These characteristics of alcoholics are visible in the relationships they share with other family members. During bouts of heavy alcohol abuse, alcoholic parents render themselves emotionally and physically unavailable to their spouse and children (Eiden, Edwards, \& Leonard, 2002). In addition, alcoholic parents are often inconsistent with the affection they give their children, vacillating between demonstrations of love and warmth at certain times and rejection at others (Woititz, 1985). In this section, we begin by describing the effect of alcoholism on the various relationships that exist in the family; then, we discuss the various experiences and outcomes that ACoA tend to display as a result of their family circumstances.

\section{Alcoholism and Relationships in the Family}

The relationship between spouses is one context that is affected by a partner's alcoholism. A variety of conflicts and communication problems tend to arise in alcoholic partnerships (Fals-Stewart \& Birchler, 1998; Kelly, Halford, \& Young, 2002) and there is a higher likelihood for detachment and reduction in intimacy than in couples without an alcoholic spouse (Carroll, Robinson, \& Flowers, 2002). In addition, the potential for verbal and physical abuse is heightened in couples with at least one alcoholic partner (Strauss \& Sweet, 1992; Quigley \& Leonard, 2000; Rodriguez, Lasch, Chandra \& Lee, 2001; Testa, Quigley, \& Leonard, 2003; Wekerle \& Wall, 2002). Individuals with an alcoholic spouse are at risk for physical and mental health issues that may be detrimental to their long-term well-being (Hurcom, Copello, \& Orford, 2000; Le Poire, 2006). Thus, couples coping with alcoholism are likely to experience a variety of personal and relational struggles. 
The relationships between parents and children can also be strained by alcoholism in direct and indirect ways. In terms of indirect influences, a dysfunctional relationship between parents can have negative implications for the children. Children are dependent on their parents for a model of appropriate behavior, one that requires a balance of warmth and control in order for them to develop their sense of self and healthy relationships outside the family (Peterson \& Hann, 1999). In alcoholic families, growing up in an environment with frequent marital strife produces a model of unhealthy relationships for children (Kelley et al., 2007). Children have been found to mimic their parents' negative interactions by expressing anger, force, and avoidance in interactions with their peers (Katz \& Gottman, 1994). In addition, children whose parents are experiencing marital distress demonstrate increased depression and decreased levels of cognitive competence compared to children with parents experiencing minimal distress (Mensah \& Kiernan, 2010). Thus, the strain that alcoholism places on spousal relationships creates an environment that can have negative repercussions for the well-being of children.

Alcoholic parents can also have a direct impact on children through their communication and relationship with the child. In families of alcoholics, excessive drinking can lead to parental manipulation (Lyon \& Greenberg, 1991), neglect, conflict, and abuse (Reich, Earls, \& Powell, 1988). In addition, many CoA experience parentification, which leads them to take on parental roles to compensate for the absence of a substance-abusing parent (Burnett, Jones, Bliwise, \& Ross, 2006). CoA can perform a variety of roles in their relationship with an alcoholic parent, including enabler, hero, lost child, mascot, and scapegoat (Vernig, 2011). As the enabler CoA facilitate the alcoholic's drinking by handling their household responsibilities and covering up for the alcoholic if they miss work or family obligations. CoA who play the role of hero are typically very mature and responsible and take it upon themselves to uphold an appearance of a 
highly functioning family for outsiders. A lost child describes CoA who are often withdrawn and prefer to be invisible within the family. The mascot, also known as the clown, refers to CoA who use humor to cope with family conflict and hardships even though they are likely suffering.

Scapegoats are CoA who often get into trouble as a means of distracting others from recognizing the underlying issues of alcoholism in the family. Thus, the relationship between CoA and their alcoholic parent can take a variety of forms, but typically reflect varying degrees of dysfunction that can be detrimental to the well-being of CoA.

The non-alcoholic parent can also play a pivotal role in impacting the development of their child. On one hand, the non-alcoholic parent can exacerbate neglect of the children if they focus all of their attention toward caring for the alcoholic parent (Reich, Earls, \& Powell, 1988). On the other hand, children's relationship with the non-alcoholic parent can be vital for providing children with the love and support they need in order to thrive. Parents who practice consistent warmth, discipline, and monitoring have been found to greatly reduce the potential for negative outcomes in CoA (Molina, Donovan, \& Belendiuk, 2010). By bolstering protective factors for CoA, such as family cohesion (Bijttebier \& Goethals, 2006), non-alcoholic parents can minimize the effects of growing up with an alcoholic parent.

\section{Experiences and Outcomes of ACoA}

Growing up in a family that is coping with a parent's alcoholism may contribute to a variety of experiences and outcomes for CoA, both in adolescence and adulthood (Molitor, Mayes, \& Ward, 2003; Pagano et al., 2007; Belles, Budde, Moesgen, \& Klein, 2011). Many ACoA have trouble expressing their feelings, often transferring their anger and resentment into forms of substance abuse, aggression in relationships, and low self-esteem (Belles, Budde, Moesgen, \& Klein, 2011; Obot \& Anthony, 2004; Rangarajan \& Kelly, 2006). Approximately 37 
percent of ACoA who seek therapy in adulthood present disorders such as anxiety and depression (Anda et al., 2002; Cuijpers, Langendoen, \& Bij1, 1999; Hibbard, 1987), especially if they witnessed high levels of marital conflict as a child (Eiden, Molnar, Colder, Edwards, \& Leonard, 2009). Moreover, growing up with an emotionally disengaged parent can lead to impaired emotional expression and regulation (Molitor, Mayes, \& Ward, 2003), complicating one's ability to handle stressful life events or carry out successful romantic relationships (Kearns-Bodkin \& Leonard, 2008). Taken together, these findings demonstrate that the emotional issues experienced as a child continue into adulthood.

ACoA also exhibit a variety of psychological outcomes of having an alcoholic parent. Psychological outcomes include poor cognitive abilities, high levels of dependency, and neuroticism (Carpenter, 1995; Roebuck, Mattson, \& Riley, 1999). Parentification is also common among ACoA because they incur a large amount of responsibility in the family and often have to take on a parental role with siblings or even their own parent (Kelley et al., 2007). As a result of having an alcoholic parent, many ACoA experience unstable attachment to family members, friends, and romantic partners (Kelley et al., 2010). Anxiety is also prevalent among ACoA, with many reporting social phobias and panic disorders (Pagano et al., 2007; Hall \& Webster, 2002). Due to the psychological implications of growing up in an alcoholic home, many ACoA find themselves in therapy or support groups to cope with the ramifications of having an alcoholic parent (Room \& Greenfield, 1993).

Emotional and psychological characteristics of ACoA can also contribute to behavioral issues for CoA. The emotional struggle of growing up in an alcoholic family often results in CoA acting out in order to receive attention (Harter \& Taylor, 2000). Many CoA demonstrate aggression and delinquent behavior (Obot \& Anthony, 2004). In addition, the anxiety that CoA 
experience often manifests in characteristics such as hyperactivity (Marshal, Molina, Pelham, \& Cheong, 2007) and eating disorders (Hibbard, 1987). In relationships, ACoA are often placaters, who become caretakers and codependents, suppressing their own emotional issues and needs to take care of others (Crandell, 1989; Hinrichs, DeFife, \& Westen, 2011). Accordingly, ACoA tend to have problems with interpersonal interaction (Baker \& Stephenson, 1995) with many reporting physical aggression and low intimacy levels in their marital relationships (KearnsBodkin \& Leonard, 2008). Finally, a behavioral outcome most relevant to ACoA is their increased likelihood of becoming substance abusers (Brook et al., 2003). Thus, ACoA tend to enact a variety of dysfunctional and anti-social behaviors.

Fortunately, some children are surprisingly resilient in the face of their parent's alcoholism. A resilient child is one who manages the stressors of growing up in a high-risk environment, turning an otherwise negative experience into a positive outcome (Garmezy \& Neuchterlein, 1972). Effective social performance and competence involves the management of stressors and the ability to successfully adapt to complicated circumstances (Masten et al., 1995). Resilient CoA appear to overcompensate for the alcoholic's behavior by taking on more responsibility and demonstrating a profound level of maturity for their age, despite being at highrisk for a variety of negative circumstances (Walker \& Lee, 1998). The factors that promote resiliency in high-risk groups remain unclear. Thus, a variety of resources may be necessary to help ACoA cope with the family disease of alcoholism and find strategies to bolster their resilience.

\section{Support for Adult Children of Alcoholics}

Social support is a way for ACoA to receive the warmth and control they may not have received consistently from an alcoholic parent. The negative experiences and outcomes that often 
result from growing up with an alcoholic parent may be easier to manage through outlets of social support that provide positive reinforcements necessary to promote recovery (Pender, 1996). Social support is a combination of verbal and nonverbal communication that is intended to help those who need assistance (MacGeorge, Feng, \& Burleson, 2011). Support has been found to reduce stress and facilitate recovery for individuals who have experienced trauma (Ikeda \& Kawachi, 2010; Jones, 2004). Support groups provide an environment where individuals coping with similar hardships can construct a climate of support and reciprocity to help each other cope with the challenges of their related situations (Greidanus \& Everall, 2010). Through the interactive processes of sharing and disclosing, support groups provide a platform for intersubjectivity, which is the knowledge that others see the world similarly to one's own viewpoint (Cohen, 1999). ACoA may communicate in support groups to make sense of their identities and issues, while sharing their stories with others who can empathize. Thus, support groups and forums are effective means by which ACoA can discuss their experiences and receive positive understanding and empathy.

Although family alcoholism is often a private matter, disclosing about one's experiences can be an important tool for making sense of and coping with the dynamics of family alcoholism. Disclosure of traumatic experiences can improve self-perceptions and decrease depression and anxiety (Hemenover, 2003). Failure to disclose distressing experiences may amplify psychological issues (Gross \& Levenson, 1993) and intensify rates of illness (Pennebaker, Kiecolt-Glaser, \& Glaser, 1988; Sloan, Marx, \& Epstein, 2005). Disclosure allows ACoA to talk through concerns or triumphs, which can potentially mitigate emotional or psychological issues stemming from their family situation (Pennebaker, 1990). Discussing the negative experiences affecting ACoA can also be an important part of the coping process (Bareket-Bojmel \& Shahar, 
2011). In fact, ACoA who enact public disclosure progressively reduce their feelings of shame and personal inadequacy (Ryan, 1991). Thus, encouraging openness and disclosure among ACoA are important strategies for helping these individuals cope with the dynamics of their alcoholic family.

One important consideration for ACoA, however, is that disclosing private information about their family may be perceived as too risky or stigmatizing. The disclosure of a specific event may greatly depend on situational factors like social acceptance and the severity of the perceived threat of disclosure (Henderson, Davison, Pennebaker, Gatchel, \& Baum, 2002). For these reasons, many ACoA may enjoy the relative anonymity that is afforded by online support groups. Online support groups provide an opportunity to anonymously speak with others who may have similar experiences and share similar feelings (Braithwaite, Waldron, \& Finn, 1999). Other potential benefits of meeting online for support are 24-hour availability, selective participation, and privacy (Walther \& Boyd, 2002; Walther \& Burgoon, 1992). Furthermore, research suggests that interactions online exhibit more direct and intimate uncertainty reduction behaviors, increased attribution confidence, and greater conversational effectiveness than faceto-face exchanges (Tidwell \& Walther, 2002). Thus, online disclosure provides ACoA with a virtual veil through which they can be present, sharing their experiences with others, while maintaining a certain level of anonymity.

\section{Research Question}

Given that ACoA may face negative repercussions stemming from their role in a family coping with alcoholism, and that online support groups provide a safe environment for sharing information and gaining insights about their family experiences, this study aims to identify the experiences and outcomes that ACoA face in adulthood. We turn to naturally occurring 
discussions in online support groups to gain insight into the experiences of ACoA. Specifically, we advance the following research question:

RQ1: What experiences do ACoA describe in their conversations with other ACoA in online support groups?

\section{Method}

This study aimed to identify themes representing the experiences and outcomes of ACoA. Narratives in the discussion threads from online support groups for ACoA included experiences and outcomes that ACoA confront as a result of coping with an alcoholic parent. Three online message boards supporting ACoA were selected for observation: (a) Sober Recovery, (b) Cyber Recovery Social Network Forum, and (c) Miracles in Progress-12-Step Forum.1 Messages on discussion boards are posted using an anonymous screen name. All screen names were removed prior to analysis, as well as any personal icons, signatures, or images that community members may include as part of their profile. Thus, the information obtained for the study was anonymous. In online message boards, a discussion thread is a compilation of an original message and the individual responses to it. The sample consisted of 61 discussion threads with a total of 504 individual posts. Several entries in the discussion threads addressed multiple issues, so we further unitized the data into discrete thematic units that addressed a single thought. This process resulted in 811 thematic units that were the units of analysis. The sample was collected over the course of two months from December 1, 2011 to January 31, 2012.2 Given that users were anonymous, we were unable to determine the distribution of gender in the sample, nor were we able to assess users' age. All forum members were self-proclaimed ACoA by virtue of their participation in the support groups, but we were unable to verify the severity of their parent's 
alcoholism, the extent to which alcoholism was chronic or acute, and the continuity of a parent's alcoholism across the lifespan.

\section{Analyses}

As a starting point, we conducted a content analysis to inductively identify themes that were present in the data (Neuendorf, 2002). We employed an inductive approach to the data because we wanted the experiences of the ACoA to drive the themes that emerged rather than imposing a theoretical schema to the data that may not resonate with ACoA's experiences. Three outside observers reviewed the online discussion threads several times to become familiar with the data; then, they conducted open and axial coding to identify dominant themes (Strauss \& Corbin, 1990). Open coding is an interpretive process designed to break down, examine, compare, conceptualize, and categorize each unit of analysis. Axial coding involves searching for overarching topics or concepts that help to organize subordinate categories into broader themes (Strauss \& Corbin, 1990). The initial review consisted of coders reading through the responses in an effort to familiarize themselves with the data. They then reviewed the data a second time locating repeated concepts and content that message board members claimed to be of particular importance. The coders then combined these topics into broader themes that accounted for conceptual overlap between topics.

Next, we wanted to verify the conceptual distinctiveness of each theme and assess the prevalence of each theme in the data. A team of two coders were trained to recognize the content of each theme within the comments. Then, each coder independently assigned a theme to each unit of analysis. The trained coders completed coding in four sets, each consisting of $25 \%$ of the data set, and met with the researchers after each set to check inter-coder reliability and resolve disagreements. Across the entire data set, the coders demonstrated $96.5 \%$ agreement and had an 
acceptable reliability $(\mathrm{K}=.937, \mathrm{p}<.001)$. Disagreements were resolved through discussion and in instances when the coders could not reach agreement about the appropriate code for a post; the first author cast the final vote.

\section{Results}

The thematic analysis revealed seven recurring themes among ACoA: a) empowerment through support, b) interference of parent in adulthood, c) connection to inner child and need to re-parent, d) low self-esteem and insecurity, e) anger and resentment, f) romantic relationship problems, and g) problems communicating. Nineteen units $(2.38 \%$ of thematic units; category $\mathrm{k}$ $=1.0$ ) were coded as miscellaneous because they were either unrelated to the discussion or too ambiguous to categorize (e.g., "I am sure, if any other person here has a problem with me, or things that I have to say, I would be told." and "I probably botched it, but maybe he'll be along to say it more clearly or maybe a search?”). The following subsections describe the content of each theme and provide excerpts from the message boards that embody each theme.

\section{Empowerment and Healing Through Support}

Support and inspiration were the most frequently mentioned themes across the message boards $(N=247 ; 30.46 \%$ of thematic units; category $\mathrm{k}=.99)$. Participation in online message boards offers individuals a place to receive and provide support in an effort to cope with personal struggles. For the ACoA, sharing stories with one another and finding individuals who related to their circumstances built rapport and appeared to reduce feelings of loneliness. As the following example demonstrates, individuals emphasized areas of overlap with other ACoA to show that they can relate and empathize with one another's experiences:

"Welcome to the site. You've got a lot on your plate, but if you can find and attend a CoDA meeting or Al-Anon meeting, you can get a sponsor and work the 12 steps. It's a tool that can help you get started on working on yourself. You might also want to try a therapist. Mine gave me greater understanding, along with motivation to make some 
changes. Wishing you the best. There is healing. None of us is or ever will be perfect, but I believe the best thing we can teach our kids is that we can change for the better. That gives them hope. When my alcoholic dad never quit even after rehab, it was hard to have hope."

Furthermore, many ACoA shared their belief in a Higher Power. To help cope with circumstances that rendered them powerless, ACoA often turned to a higher power for strength. For example, the following ACoA indicated the need to rely on a Higher Power to cope with change in his or her life:

"I can see that I am oscillating between the old and the new, and the in between place is very uncomfortable. This is because I need to rely on a power greater than me. It requires large amounts of faith and trust - no wonder change can be stressful, especially for adult children."

Due to the stigma of being an ACoA, members of the support groups seemed to greatly benefit from the medium of online support. The online forums provided a connection to a large network of others who could relate to their experiences. Furthermore, ACoA described several reasons for participating in support groups versus therapy. Support groups were described as sources of comfort, identification, connection, and coping. The post below suggests a preference for online support compared to face-to-face support groups, where an online forum may provide greater comfort in disclosing one's life stories:

"I have but don't go to [FtF meetings] regularly. Online seems more personal, if you can believe that."

Thus, these examples illustrate that ACoA find a great deal of support and comfort in the online forums and their belief in a higher power gives them the strength to move forward.

\section{Interference of Parent in Adulthood}

The second most frequent theme across the posts were the ways that alcoholic parents still interfered with ACoA in adulthood $(N=171 ; 21.09 \%$ of thematic units; category $\mathrm{k}=.93)$. 
Many ACoA's parents never reached recovery. Some ACoA needed to be caretakers for their parents and others chose to remove themselves from the family entirely. Even for those whose parents have since died, ACoA indicated that their parent still had an influence on them because the child was unable to experience closure from their childhood trauma. Regardless of the space between family members, the experience of growing up in an alcoholic family continued to affect them. In the following example, the ACoA laments that he or she seems to be more affected by a parent's alcoholism in adulthood than during childhood:

"The hardest thing for me growing up with a mother who was an alcoholic and a smoker was just seeing it everyday. Drinking and smoking just seemed to be a normal to me. IMO [in my opinion] it affects me more now at age 49 (she been drinking 40+ years) than it did as a kid because I can see the damage she has left in her wake."

Another feature of the message board discussions are the reflections of how the alcoholic parent still continues to say things and behave in ways that are hurtful to the ACoA. This is demonstrated in the following post when the ACoA explains that as he/she is making progress in his/her own recovery in adulthood the mother's behavior presents new obstacles:

"My wife says my mother is not mentally capable of admitting to all the bad things that happened and I should do my best to forgive her and move on. I just about get there and then her head opens up, the snakes come out, and she says the most outrageous things, I try hard to limit my contact with her, but if I want to spend time with my dad I have to tolerate her for limited periods."

For many ACoA it was not until adulthood that they finally became aware of the effects of their parents' alcohol problem. Once they have the maturity and experience to recognize the level of dysfunction that existed in their family they seemed to finally make sense of and realize the severity of their parents' illness. In the example below, an ACoA begins to identify how the dysfunctional features of his/her parents' relationship continues to be problematic later in life:

"She never accepted it when he said it was a disease, thought it was psychobabble and an excuse. But overall she has always supported (enabled?) my dad by staying with him 
even after they divorced legally. I am just beginning to unravel how all of this is affecting me in my adult life."

These examples illustrate that the aftermath of an alcoholic parent persists into adulthood and many ACoA must still navigate relationships with an alcoholic parent who never sought recovery.

\section{Connection to Inner Child and Need to Re-parent}

ACoA repeatedly expressed a need to protect their wounded inner child $(N=145$;

$17.88 \%$ of thematic units, category $\mathrm{K}=.91)$. Many ACoA recalled a large burden of responsibility during childhood that affected their ability to develop a strong sense of self. Now in adulthood, ACoA feel they need to nurture their inner child and continue to search for ways to satisfy childhood needs. The excerpt below exemplifies the sense of urgency in protecting one's inner child from further harm and in turn trying to cope with their deeply rooted issues:

"Once I've got over my mood, which is usually caused by my inner child trying to run my life, I can be more objective about the situation. The problem for me, is not so much about money, but about relationships, and my part in them, and how I need to protect the wounded inner child from triggers. This I know is my responsibility, not anyone elses."

Among the problems that ACoA related to their childhood development was the need to make sure everything was perfect at home in an effort to appease alcoholic parents. Similarly, ACoA noted being highly critical of themselves, feeling as though they were not capable of accomplishing even the smallest goal. In the following post, an individual references the struggle of managing their inner child:

"I feel like a child trying to live and interact in an adult world. Wanting to be responsible, accountable, and considerate, but still very immature, childish, irresponsible and self centered to the core."

ACoA also discussed parentification as one of the issues that prevented them from nurturing their inner child. Parentification was described as fulfilling parental roles and 
responsibilities, including taking care of one's own parent, in an effort to maintain family stability. Thus, individuals who were parentified as children often continue this trend into adulthood by trying to keep family members together and continuing to take care of their parents, as described in the following post:

"When a child is thrust into adulthood, responsibilities, realities and sacrifice, then the child never learns how to relax and enjoy life. It is really all they know. Sometimes, as an adult, they have to mourn the loss of that childhood, but all too often, they can't. They became the 'Little Adult' as a means of survival, both physically and more importantly, mentally. I too am one of those children. I always feel guilty if I allow that stuffed away child to come out and play."

A final repercussion of the inner child struggle is the notion of re-parenting. As it is described in the online forums, re-parenting involves learning how to properly function as an adult, something ACoA may not have had a frame-of-reference for while growing up. The following excerpt demonstrates how the ACoA had to relearn the meaning of several emotionally charged words due to the fact that his or her parents never provided him or her with an appropriate model for what these ideas really meant:

"My problem is that I was using the wrong version of the word 'Forgiveness'. Recovery has taught that as a child I learned how to deal with the world while living in a horribly toxic environment. Part of the 'toxic' stuff I absorbed was the definitions of words. Words like 'love', 'happiness', 'help', and 'forgiveness' I learned from them. The crazy, toxic people. When I grew up I still had those incorrect definitions stuck to me like parasites. I had to learn the real definition of those words, which I did by listening to people in meetings, reading recovery literature, and a couple of good therapists."

Coping with the effects of having an alcoholic parent is an ongoing process for ACoA. The ACoA recovery process involves addressing the needs of the inner child and utilizing resources like online message boards to re-parent themselves.

\section{Low Self-esteem and Insecurity}


Problems with self-esteem and feelings of insecurity appeared in many message board posts $(N=117 ; 14.43 \%$ of thematic units; category $\mathrm{k}=.93)$. The ACoA often suggested that they had a low emotional IQ, which increased their levels of uncertainty and insecurity because they were always questioning whether their feelings were relevant or accurate. The inability to cope with uncertainty often contributed to stress, which was often associated with feelings of being overwhelmed by life, lethargy, and giving up. The text below highlights the struggle one ACoA has trying to function in society, debilitated by his or her poor self-confidence:

"I sooo know what you're going through, it's been such a struggle for me since I've been old enough to work. I 'know' I can do the job, physically, but emotionally it's a completely different story!! I am terribly insecure and I cry at job interviews because I do NOT believe in myself at all. I've been an "unemployed workaholic" for years now, going stir crazy because I can't seem to progress myself."

In terms of insecurity, ACoA reported minimal disclosure to others about their issues, as well as hypervigilence regarding whom they allowed themselves to feel vulnerable around. Feelings were repressed for fear of rejection or guilt of having such feelings in the first place. In addition, ACoA would frequently blame themselves for the alcoholic's problems or for dissolving intimate relationships. In the post below, the ACoA recognizes how his or her negative behavior traces back to the interactions with an alcoholic mother. By removing some of the blame, the ACoA can see how the pattern developed into a defense mechanism, and the effect this has on his or her ability to interact with others. The post below acknowledges that interactions with his or her alcoholic parent was the source of some insecurities:

"I realized that, growing up, a difference in taste or preference, or opinion, meant a fight or argument to defend what I liked, and that it was always a no-win situation. Even if I pretended to agree eventually, it was still a reason that my mom used to make me feel stupid and embarrassed, and to humiliate me. So now, I go around trying to make people feel bad for liking different things than the things I like, before they have a chance to make me feel bad first." 
Thus, ACoA may struggle to become confident and secure individuals in adulthood because they received inconsistent messages in their family and never learned to trust their own abilities or feelings.

\section{Anger and Resentment}

Another common theme in the online discussion threads was anger and resentment $(N=$ $51 ; 6.29 \%$ of thematic units; category $\mathrm{K}=.77)$. In particular, ACoA expressed anger and resentment toward parents, including both the alcoholic parent and the enabling parent. Evidence of $\mathrm{ACoA}$ frustration is displayed in the following excerpt in which the ACoA describes feeling resentful of his or her mother for having a problem and for passing her problems on to her children:

"Society tells us that our parents can never do wrong and it's absolutely the WORST thing in the world to be angry/hurt by our parents and not to speak to them. But that's 'normal' parents, ie, parents who sacrifice and love their children unconditionally, not the kind WE grew up with. I struggle with this BAD for that reason and also because I live with my mom. Sigh. She 's very sick, made ME very sick, and I resent the@\#\$@out of her. (and people telling me I shouldn't makes it worse)."

Many ACoA expressed a feeling of anger toward at least one parent, with several of those also expressing secondary emotions. Secondary emotions always seemed to lie beneath the anger they felt, such as feeling hurt by their parents. Other emotions were expressed when discussing anger towards their parents such as apathy and sympathy. As demonstrated below, there was a sense that moving on and separating themselves from their family was the best solution to their anger issues. The anger that may have existed has now turned to compassion and understanding, realizing that they are not the only ones who have been affected:

"I haven't spoken much to any of my parents or siblings in 3 or 4 years now, and I'm pretty happy with that. I don't feel that I hate them anymore. Even the one in particular who ticks me off to no end, who I might even say I sort of dislike. But I don't hate them. I think I feel compassion for them, and understanding that they're all victims, too." 
Anger and resentment appeared to be a common outcome of growing up in an alcoholic home and these feelings sometimes grew into compassion or empathy for the alcoholic parent. Through discussion, ACoA acknowledged these emotions and identified ways to effectively address the hurt they felt.

\section{Romantic Relationship Problems}

Consistent with prior research on ACoA, another theme to emerge from the data revealed that ACoA had difficulty developing healthy intimate relationships in adulthood $(N=38 ; 4.69 \%$ of thematic units; category $\mathrm{k}=.95)$. One recurring aspect of this theme was that ACoA often expressed the desire to "fix" their romantic partner. Many of the ACoA recognized that their desire to fix current romantic partners stemmed from their desire to fix their parents when they were children. The notion of fixing or changing someone is evident in playing the role of enabler, a role that some of the ACoA saw themselves or a parent play during their childhood. In the following post, the ACoA explains how his or her inability to fix an alcoholic mother led to finding romantic partners in adulthood that needed fixing in order to feel a sense of success in helping someone who may or may not have needed help:

"If I make a list of the problems my former boy friends had, it'll overwhelm any psychiatry hospital and I dealt with all that alone! For me, the wish to fix them was connected to my incapacity of "fixing" my mother. I was programmed to believe that I could if I only wanted or tried harder, make mom not drink anymore. If I only was clever enough, I surely could have fixed things so good that my Dad would not have gotten mad on her and beat her. God knows I tried! I failed. So I looked for another someone to fix, hoping I'll succeed and he will heal and I will have accomplished my duty, close the chapter and be able to move on. I needed to save people more than they needed to be saved."

Conversely, the ACoAs also expressed the need to seek approval and feel a sense of security from their partner. Along these lines, another relational problem that emerged was fear 
of abandonment. ACoAs expressed frustration in their inability to control their partner or the relationship and often feared that the relationship may end. The majority of posts that referenced a romantic partner described a relationship on the brink of dissolution:

"I feel like I have went backwards... not feeling loveable, not feeling secure, absolutely scared to be alone, but wanting to isolate. Like a child I react to life by throwing my bottle from the high chair to the floor and screaming... I am attracted to the most unavailable people, I trust untrustworthy people, and fear of abandonment has me holding on to relationships that bring more pain than joy."

The romantic relationship problems experienced by ACoA reflect the unhealthy interactions they had with their alcoholic parent. The fear that resulted from the relationship with the alcoholic parent often led to relationship problems in adulthood.

\section{Problems Communicating}

ACoA expressed poor communication in several posts $(N=23 ; 2.84 \%$ of thematic units; category $\mathrm{K}=.96$ ), particularly in reference to their relationships. Communication at home was either non-existent or hostile for many ACoA. Therefore, the ways in which ACoA communicated in their own relationships were similar to their alcoholic parents. In the following post, one individual notes the struggle to communicate effectively and where these issues stem from:

"I still need more practice communicating...Standing up for myself...I also need to do it calm and assertively... I can easily lose my temper...It's the way my father was with me...It passed on to me...I will change it."

Another aspect of communication problems among ACoA was reflected in their inability to express themselves. Many ACoAs noted that while growing up they were told not to communicate about what was bothering them and not to discuss the problem of alcoholism at all. The excerpt below conveys the way in which communication was stifled surrounding the topic of alcoholism in one ACoA's home: 
"It was not repressed or suppressed memories - we all remembered just fine. But no one would talk about it openly. People who have been long dead aren't talked about. People who are still living aren't talked about. Actions and behaviors aren't talked about."

Another post reflects on the ramifications of not communicating about the alcoholism in the family. In the post, the ACoA suggests that the lack of communication surrounding the problem inevitably increases the length of time the alcoholism will affect members of the family:

"Things can still be traumatic. And the pain is not something many people are willing to talk about - silence is just a way of forgetting. But I guess you are seeing how keeping quiet about events doesn't negate their power to effect people - if anything, the repercussions thrive in the darkness, where life is unexamined. The trade off for ignoring pain is usually prolonging it."

As previously discussed, insecurities and low self-esteem are primary characteristics of being an ACoA; however, the excerpts presented in this study represent ACoAs who are trying to communicate and express themselves more effectively. The online message boards provide a secure place for them to discuss their guilt and fears without being identified visually. The post below exemplifies how many ACoA are working on their communication abilities in order to feel more comfortable discussing their experiences with alcoholism. This ACoA describes his or her effort to incorporate communication to improve him or herself and reduce the amount of stigma surrounding what it means to be a child of an alcoholic:

"In the early to mid 70s, rape victims were usually treated as social pariahs and blamed for being victims. A cultural shift happened as the result of more and more victims being fed up with being told it was their fault. The victims started talking, and the more who spoke loudly, the less the world vilified the victim. I am a victim and I will talk. I hope that eventually this subject will stop being so taboo and more of us can speak freely. Until that time comes, we will talk in hushed voices and make excuses and cover up to all except the others who understand us." 
The lack of communication in families of alcoholics not only prevented recovery but also the ability to express oneself. The message boards enable ACoA to practice their communication skills and through discussion discover the benefits of communicating their experiences.

\section{Discussion}

This study analyzed online discussions among ACoA to identify the experiences and outcomes that they face in adulthood. The results revealed seven main themes among ACoA, including: a) empowerment through support, b) interference of parent in adulthood, c) connection to inner child and need to re-parent, d) low self-esteem and insecurity, e) anger and resentment, f) romantic relationship problems, and g) problems communicating. The results have important implications for understanding the experiences of ACoA and the long-term impact of family communication on individual well-being. The findings add to the existing literature on families coping with alcoholism by identifying particular issues they face. Much of the available research on CoA has focused on the psychological adjustment of young children who are still living in a home with their alcoholic parent (see Slutske et al., 2008; Heitzeg, Nigg, Yau, Zucker, \& Zubieta, 2010). Less is known about the long-term implications that having an alcoholic parent can have on people once they reach adulthood (see Richards \& Nelson, 2012; Osterndorf, Enright, Holter, \& Klatt, 2011; Kelley et al., 2010). Thus, this study has implications for understanding the broader reaching effects of family alcoholism for CoA into adulthood and developing strategies to help ACoA cope with their situation and foster resiliency.

\section{Experiences and Outcomes Facing ACoA}

This study highlights the experiences and outcomes that ACoA cope with in adulthood, which suggests that alcoholism is a condition that has far-reaching effects on the lives of those who have had first-hand exposure to the disease. Several of the themes emerging from this study 
highlight problems coping with emotions. Specifically, the ACoAs in the message boards revealed anger, resentment, insecurity, and low self-esteem. The experience of traumatic events in childhood or adulthood can lead to the suppression of emotions and even fear of expressing one's feelings (Fewell, 2011; Middelton-Moz, \& Dwinell, 2010), which can be detrimental to an ACoA's ability to convey affect and engage intimately with others. Many ACoA noted that they tended to lash out at others when they felt threatened or retreat into feelings of helplessness. Thus, one prominent concern for ACoA is the prevalence of negative emotion and their inability to cope with emotional overload. The inability of ACoAs to manage more nuanced emotional experiences left them feeling somewhat stunted in their emotional development.

Emotion regulation theory appears to be a particularly relevant framework for examining the emotional experiences and outcomes of ACoA. Looking across themes, one commonality is that ACoA seem to struggle with emotions, stemming from their interactions with parents, which affects relationships later in life. One of the ways that parents can influence children's ability to express emotions is through a cold parenting style (Gottman \& Katz, 1989). Cold parenting is a form of emotion-dismissing communication as opposed to emotion-coaching communication (Gottman, Katz, \& Hooven, 1997). Emotion-dismissing communication refers to parents that may dismiss, criticize, and belittle children during expressions of emotion. Emotion-coaching communication describes parents who view a child's expression of emotion as an opportunity to teach ways of effectively managing emotion. Alcoholic parents are likely to engage in more emotion-dismissing communication to the extent that they attempt to stifle uncomfortable conversations about alcoholism or problems in the home (Black, 1982). Individuals who grow up in an emotion-coaching home receive better training in conflict and are more likely to carry that healthy model into their own intimate relationships, as opposed to children with emotion- 
dismissing parents (Cupach \& Olson, 2006). Children of emotion-dismissing parents have been found to be less healthy, have poorer academic records, and show more behavioral problems (Gottman, Katz, \& Hooven, 1997). Interventions and programs for families coping with alcoholism should work with family members to encourage the recognition, expression, and acceptance of emotional reactions to interpersonal events.

ACoA also highlighted issues stemming from their appraisals and attributions of their family circumstances. One notable theme reflected the continued interference of an alcoholic parent into adulthood. This theme is interesting because it highlights the ACoA's perceptions of the locus of control in their situation. Most ACoA continued to see the ways that their alcoholic parent impinged on their lives and impeded their goals, but few recognized the role they played in that relationship by allowing their parent to have so much influence. Thus, ACoA tended to have somewhat biased attributions for their situation, often blaming their parent for interfering in their well-being rather than accepting some responsibility for their circumstances. Similar to the non-alcoholic spouse (Hinkin \& Kahn, 1995), ACoA enabled the alcoholic to continue their behavior, which in turn allowed themselves to continue to be affected by the disease.

The message boards also revealed a great deal of intense cognitive reflection. Many ACoA used the message boards as a way of making sense of their situation and the events that contributed to their current emotional and psychological state. One important theme that many ACoA identified was the sense that they missed out on their childhood due to demands on them to be mature and responsible family members. Many ACoA were only recently beginning to reflect on the ways that they had been asked to shoulder more than their fair share of responsibility for maintaining their family during childhood and recognized a need in adulthood to nurture their child within. The inner child concept describes the underdeveloped identity many 
ACoA feel because of parental neglect or heavy burdens of responsibility atypical of most children (Kelley et al., 2007). These conclusions are consistent with previous findings that ACoA identify most strongly with the role of caretaker in the family and experience increased parentification (Crandell, 1989; Vernig, 2011). Parentification is a role reversal between parent and child, where children act as parents to their own mother or father (Afifi \& Hamrick, 2006). Notably, this heightened reflection is likely indicative of the type of ACoA that seeks support in online forums, such that individuals who seek support are more likely to engage in cognitive reflection about their situation than individuals who avoid support forums.

The themes also reflected significant issues with communication and developing relationships. Most of the ACoA attributed their difficulties in these areas to the fact that they lacked strong role models in their parents. Given that the ACoA grew up in homes often characterized by dysfunctional communication behaviors and unhealthy relationships, they often found themselves in adult relationships that mirrored the patterns they witnessed as children. Many ACoA admitted to forming relationships with abusive partners or with partners who needed "fixing" as a way of continuing the habits they formed in dealing with an alcoholic parent. In addition, the ACoA struggled to communicate in their adult relationships in ways that promoted healthy bonds. Many of them struggled to manage conflict effectively and reported difficulty asking for what they needed from relationship partners. Other studies have similarly found that relationship satisfaction among ACoA is lower and the need for control is greater than adults with non-alcoholic parents (Harrington \& Metzler, 1997; Beesley \& Stoltenberg, 2002). These relational and communicative problems have implications for ACoAs' ability to break the cycle of dysfunctional relationship behaviors that seem normative given their upbringing. 
One explanation for the poor romantic relationship experiences that ACoA have in adulthood may stem from the attachment styles they developed as a result of growing up with an alcoholic parent. According to attachment theory (Bowlby, 1969), a primary caregiver's availability and sensitivity during infancy and early childhood shapes children's internal representations of self. Thus, caregivers who are available and respond sensitively to their children's distress influence their evaluation of the self as worthy of attention and affection, but parents who fail to provide sensitive and responsive care could promote a model of self as unworthy and undeserving of attention and love. Within the context of an alcoholic family, caregiving quality may be compromised by parents' preoccupation with their own or their partner's alcoholism. For example, alcoholics tend to prioritize alcohol over family, neglect family and work obligations, become verbally and physically abusive, and withdraw from loved ones (Schade, 2006). Moreover, during bouts of heavy alcohol abuse, alcoholic parents often render themselves emotionally and physically unavailable to their spouse and children (Eiden, Edwards, \& Leonard, 2002). When a parent's attention to children is impaired by these factors, children may react in disorganized, detached and disruptive ways and they may also develop insecure attachment (Erdman, 1998), which may render them anxious and avoidant in their adult relationships. Additional research is needed to better understand the attachment styles that children develop after growing up with an alcoholic parent and the impact of their attachment on their romantic relationship experiences.

\section{Implications for Supporting ACoA}

The results of this study have several practical implications. The themes that emerged from analysis provide helpful information for ACoA and health professionals. For ACoA, the study acknowledges that they are not alone in their experiences and outcomes. Many ACoA 
expressed a feeling of loneliness, believing that their family was the only one dealing with so much dysfunction. Fortunately, through online disclosure they found that many ACoA could relate to what they were going through. Support plays a significant role in how people build their self-esteem and cope with personal struggles (Burleson, 1994; Greidanus \& Everall, 2010). Thus, ACoA should be encouraged to seek support or professional assistance to recognize and address the negative effects of growing up in a family with alcoholism. Overall, the study highlights the similarities across the experiences of ACoA, and that communication acts as an important tool for coping and helping ACoA to improve their well-being.

This study also highlights the importance of online support groups as a tool for helping ACoA cope. For many of the ACoA, the online message boards acted as a forum to improve their communication and ability to form relationships. The message boards reiterated the importance of reflection and disclosure for fostering feelings of empowerment and support. The anonymity of the boards allowed ACoA to establish who they are at a rate they are comfortable with and provide them with a place where they do not need to feel threatened by disclosing their difficult experiences. The study provides further support for the benefits of computer mediated communication and adds to the populations that have been observed in online communities.

The results of this study also point to a number of important ethical considerations for both children and parents in alcoholic families. Ethical theory points to virtue ethics as the character or virtue motives that make someone "good," and duty ethics as the rules and actions that make someone "right." Encompassed as part of duty ethics is deontological ethics, which suggest that what makes something right versus wrong, or good versus bad, is that it conforms to some rational duty and that all people have a responsibility to fulfill duties to the self and others (Sullivan, 1995; Waller, 2005). Some of the main obligations that people face as part of 
deontology fall under the rubric of care ethics, which involves supporting relationships and caring for others, especially those who have a high need for support (Slote, 2007). The responses from the ACoA in this study reflect a certain degree of parental neglect of their moral obligation to care for their children and attend to their responsibilities as parents. In contrast, ACoA in this study were somewhat conflicted in terms of the extent of their own ethical responsibilities to care for an alcoholic parent and what that care should look like. The responses from ACoA also reflected challenges associated with virtue ethics, in terms of their ability to achieve selfactualization and embody actions that make them feel like good and worthy people in society. As family counselors and therapists work with ACoA, it may be necessary to probe their perceptions of the extent to which their parents fulfilled their responsibilities as caretakers and to point to the ways in which the ACoA's own caretaking in the family contribute to their personal virtue. As many of the responses in this study showed, ACoA often struggle with resentment and low selfesteem; thus, helping ACoA to recognize the ethical implications of their own and their parents' behavior may be a good starting point for resolving negative views of the self and the family.

\section{Strengths, Limitations, and Future Directions}

This study has several strengths. First, the message boards provide a useful platform for observing naturally occurring discussion in the voices of ACoA, free from researcher influence. Because the ACoA were anonymously communicating with their peers, they were able to discuss issues that they may not have discussed in the context of a research laboratory or even in face-toface groups. Second, we analyzed a total of 811 thematic units, which is a relatively large sample for qualitative analysis.

This study also has some limitations. One limitation is that the ACoA who participate in online support groups are actively trying to cope with the challenges of having an alcoholic 
family member. ACoA who do not turn to support groups for help may have different hardships that are not represented in the data. Another limitation is in the anonymous nature of the study, making it impossible to document differences due to demographic characteristics or the severity of a parent's alcoholism. Analysis of the online message boards also presents the challenge of confirming the nature of the parent's alcoholism. It is possible that participants exaggerate or downplay certain aspects of their parent's alcoholism in the context of an online forum. This study also falls short of documenting the actual communication behaviors that exist in families of alcoholics and the influence that communication has on the long-term emotions and cognitions of ACoA. Although identifying the issues that ACoA face in adulthood is a good starting point for examining the effect of these factors on interpersonal communication and adjustment, additional research is needed to explore how these challenges affect interpersonal behavior.

The results of this study point to two recommendations for future research. First, we look forward to research that surveys ACoA about their family experiences more directly and explores the manifestations of their struggles in their communication behavior. Second, future research on families coping with alcoholism and the experiences of ACoA would benefit from drawing on theoretical approaches in interpersonal communication. There are obvious applications of family systems theory and attachment theory, but there is also room to expand other theoretical views to this context, such as Petronio's (2002) communication privacy management theory, Fitzpatrick and Koerner's (2002) family communication patterns theory, and LePoire's (2006) inconsistent nurturing as control theory. Families coping with alcoholism are an understudied group that would benefit from research that can develop theoretically derived interventions to help them manage their well-being across the lifespan. 


\section{References}

Ackerman, R. J. (1986). Growing in the shadow. Pampano Beach, FL: Health Communications.

Afifi, T., \& Hamrick, K. (2006). Communication processes that promote risk and resiliency in post divorce families. Handbook of divorce and relationship dissolution, 435-455.

Alcohol and Drug Programs, Resource Center. (2007). Children of alcoholics: Important fact (99-2567).

Anda, R. F., Whitfield, C. L., Felitti, V. J., Chapman, D., Edwards, V. J., Dube, S. R., \& Williamson, D. F. (2002). Adverse childhood experiences, alcoholic parents, and later risk of alcoholism and depression. Psychiatric Services, 53, 1001-1009.

Baker, M., \& Stephenson, L. A. (1995). Personality characteristics of adult children of alcoholics. Journal of Clinical Psychology, 51, 694-702.

Bareket-Bojmel, L., \& Shahar, G. (2011). Emotional and interpersonal consequences of selfdisclosure in a lived, online interaction. Journal of Social and Clinical Psychology, 30, 732-759.

Beesley, D., \& Stoltenberg, C. D. (2002). Control, attachment style, and relationship satisfaction among adult children of alcoholics. Journal of Mental Health Counseling, 24, 281-298.

Belles, S., Budde, A., Moesgen, D., \& Klein, M. (2011). Parental problem drinking predicts implicit alcohol expectancy in adolescent and young adults. Addictive Behaviors, 36, 1091-1094.

Bijttebier, P., \& Goethals, E. (2006). Parental drinking as a risk factor for children's maladjustment: The mediating role of family environment. Psychology of Addictive Behaviors, 20, 126-130. 
Black, C. (1982). It will never happen to me. Denver, CO: MAC Printing and Publications Division.

Bowlby, C. (1969). Attachment and loss (Vol. 1). New York: Basic.

Braithwaite, D. O., Waldron, V. R., \& Finn, J. (1999). Communication of social support in computer-mediated groups for persons with disabilities. Health Communication, 11, 123151.

Brook, D. W., Brook, J. S., Rubenstone, E., Zhang, C., Singer, M., \& Duke, M. R. (2003). Alcohol use in adolescents whose fathers abuse drugs. Journal of Addictive Diseases, 22, 11-34.

Burleson, B. R. (1994). Comforting messages: Features, functions, and outcomes. In J. A. Daly \& J. M. Wiemann (Eds.), Strategic interpersonal communication (pp. 135-161). Hillsdale, NJ: Erlbaum.

Burnett, G., Jones, R. A., Bliwise, N., \& Ross, L. T. (2006). Family unpredictability, parental alcoholism and the development of parentification. American Journal of Family Therapy, $34,181-189$.

Carpenter, D. R. (1995). Adult children of alcoholics: CAQ profiles. Alcohol Treatment Quarterly, 13, 63-70.

Carroll, J. J., Robinson, B. E., \& Flowers, C. (2002). Marital estrangement, positive feelings toward partners and locus of control: Female counselors married to alcohol-abusing and non-alcohol-abusing spouses. Journal of Addictions \& Offender Counseling, 23, 30-40.

Cohen, D. J. (1999). Adding insult to injury: Practices of empathy in an infertility support group. New Brunswick, NJ: Rutgers University. 
Crandell, J. S. (1989). Brief treatment for adult children of alcoholics: Accessing resources for self-care. Psychotherapy, 24, 510-513.

Cuijpers, P., Langendoen, Y., \& Bijl, R. V. (1999). Psychiatric disorders in adult children of problem drinkers: Prevalence, first onset, and comparison with other risk factors. Addiction, 94, 1489-1498.

Cupach, W. R., \& Olson, L. N. (2006). Emotion regulation theory: A lens for viewing family conflict and violence. In D. O. Braithwaite \& L. A. Baxter (Eds.), Engaging Theories in Family Communication (pp. 213-228). Sage Publications Ltd.

Dayton, T. (2009). Adult children of alcoholics ACoAs: Qualities and Traits. Huffington Post, Sept. 2009.

Diaz, R., Antoni, G., Garcia, M., Arnau, J., Pascual, F., Canuelo, B., Rubio, G., \& de Mios, Y. (2008). Children of alcoholics in Spain: from risk to pathology. Social Psychiatry and Epidemiology, 43, 1-10.

Drejer, K., Theikjaard, A., Teasedale, T. W., Schulsinger, F., \& Goodwin, D. W. (1985). A prospective study of young men at high risk for alcoholism: Neuropsychological assessment. Alcoholism: Clinical and Experimental Research, 9, 498-502.

Eiden, R. D., Edwards, E. P., \& Leonard, K. E. (2002). Mother-infant and father-infant attachment among alcoholic families. Development and Psychopathology, 14, 253-278.

Eiden, R. D., Molnar, D. S., Colder, C., Edwards, E. P., \& Leonard, K. E. (2009). A conceptual model predicting internalizing problems in middle childhood among children of alcoholic and nonalcoholic fathers: The role of marital aggression. Journal of Studies on Alcohol and Drugs, 70, 741-750. 
Erdman, P. (1998) Conceptualizing ADHD as a contextual response to parental attachment. American Journal of Family Therapy, 26, 177-85.

Fals-Stewart, W., \& Birchler, G. R. (1998). Marital interactions of drug-abusing patients and their partners: Comparisons with distressed couples and relationship to drug-using behavior. Psychology of Addictive Behaviors, 12, 28-38.

Fewell, C. H. (2011). An attachment and mentalizing perspective on children of substanceabusing parents In S. L. A. Straussner \& C. H. Fewell (Eds.), Children of SubstanceAbusing Parents: Dynamics and Treatment. New York, NY: Springer Publishing Company.

Fitzpatrick, A. F., \& Koerner, M. A. (2002). Toward a theory of family communication. Communication Theory, 12, 70-91.

Garmezy, N., \& Nuechterlein, K. H. (1972). Invulnerable children: The fact and fiction of competence and disadvantage. American Journal of Orthopsychiatry, 42, 328-329.

Gottman, J. M., \& Katz, L. F. (1989). Effects of marital discord on young children's peer interaction and health. Developmental Psychology, 13, 246-252.

Gottman, J. M., Katz, L. F., \& Hooven, C. (1997). Meta-emotion: How families communicate emotionally. Mahwah, NJ: Lawrence Erlbaum.

Greidanus, E., \& Everall, R. D. (2010). Helper therapy in an online suicide prevention community. British Journal of Guidance and Counseling, 38, 191-204.

Gross, J. J., \& Levenson, R. W. (1993). Emotional suppression: Physiology, self-report, and expressive behavior. Journal of Personality and Social Psychology, 64, 968-970.

Hall, C. W., \& Webster, R. E. (2007). Multiple stressors and adjustments among adult children of alcoholics. Addiction Research and Theory, 15, 425-434. 
Hall, C. W., \& Webster, R. E. (2002). Traumatic symptomatology characteristics of adult children of alcoholics. Journal of Drug Education, 32, 195-211.

Harrington, C. M., \& Metzler, A. E. (1997). Are adult children of dysfunctional families with alcoholism different from adult children of dysfunctional families without alcoholism? A look at committed, intimate relationships. Journal of Counseling Psychology, 44, 102107.

Harter, S. L., \& Taylor, T. L. (2000). Parental alcoholism, child abuse, and adult adjustment. Journal of Substance Abuse, 11, 31-44.

Heitzeg, M. M., Nigg, J. T., Yau, W. Y., Zucker, R. A., \& Zubieta, J. K. (2010). Striatal dysfunction marks preexisiting risk and medial prefrontal dysfunction is related to problem drinking in children of alcoholics. Biological Psychiatry, 68, 287-295.

Hemenover, S. H. (2003). The good, the bad, and the healthy: Impacts of emotional disclosure of trauma on resilient self-concept and psychological distress. Personality and Social Psychology Bulletin, 29, 1236-1244.

Henderson, B. N., Davison, K. P., Pennebaker, J. W., Gatchel, R. J., \& Baum, A. (2002). Disease disclosure patterns among breast cancer patients. Psychology and Health, 17, 51-62.

Hibbard, S. (1987). The diagnosis and treatment of adult children of alcoholics as a specialized therapeutic population. Psychotherapy, 24, 779-785.

Hinkin, C. H., \& Kahn, M. W. (1995). Psychological symptomatology in spouses and adult children of alcoholics: An examination of the hypothesized personality characteristics of codependency. Journal of Substance Use \& Misuse, 30, 843-861.

Hinrichs, J., DeFife, J., \& Westen, D. (2011). Personality subtypes in adolescent and adult children of alcoholics. The Journal of Nervous and Mental Disease, 7, 487-498. 
Hurcom, C., Copello, A., \& Orford, J. (2000). The family and alcohol: Effects of excessive drinking and conceptualizations of spouses over recent decades. Substance use and misuse, 35, 473-502.

Ikeda, A., \& Kawachi, I. (2010). Social networks and health. In A. Steptoe (Ed.), Handbook of behavioral medicine: Methods and applications (pp. 237-262). New York: Springer.

Jones, S. M. (2004). Putting the person into person-centered and immediate emotional support: Emotional change and perceived helper competence as outcomes of comforting in helping situations. Communication Research, 31, 338-360.

Katz, L., \& Gottman, J. M. (1994). Patterns of marital interaction and children. In R. D. Parke \& S. G. Kellam (Eds.), Exploring Family Relationships With Other Social Contexts (pp. 4974). Hillsdale, NJ: Lawrence Erlbaum Associates.

Kearns-Bodkin, J. N., \& Leonard, K. E. (2008). Relationship functioning among adult children of alcoholics. Journal of Studies on Alcohol and Drugs, 69, 941-950.

Kelley, M. L., Braitman, A., Henson, J. M., Schroeder, V., Ladage, J., \& Gumienny, L. (2010). Relationships among depressive mood symptoms and parent and peer relations in collegiate children of alcoholics. American Journal of Orthopsychiatric Association, 80, 204-212.

Kelley, M. L., French, A., Bountress, K., Keefe, H. A., Schroeder, V., Steer, K., Fals-Stewart, W., \& Gumienny, L. (2007). Parentification and family responsibility in the family of origin of adult children of alcoholics. Addictive Behaviors, 32, 675-685.

Kelly, A. B., Halford, W. K., \& Young, R. M. (2002). Couple communication and female problem drinking: A behavioral observation study. Psychology of Addictive Behaviors, $16,269-271$. 
LePoire, B. A. (2006). Family communication: Nurturing and control in a changing world. CA: Sage Publications.

Lyon, D., \& Greenberg, J. (1991). Evidence of codependency in women with an alcoholic parent: Helping out Mr. Wrong. Journal of Personality and Social Psychology, 61, 435439.

MacGeorge, E. L., Feng, B., \& Burleson, B. (2011). Supportive communication. In M. L. Knapp \& J. A. Daly (Eds.), Handbook of interpersonal communication (pp. 317-354). Thousand Oaks, CA: Sage.

Marshal, M. P., Molina, B. S., Pelham, W. E., \& Cheong, J. (2007). Attention-deficit hyperactivity disorder moderates the life stress pathway to alcohol problems in children of alcoholics. Alcoholism, Clinical, \& Experimental Research, 31, 564-574.

Masten, A. S., Coatsworth, J. D., Neemann, J., Gest, S. D., Tellegen, A., \& Garmezy, N. (1995). The structure and coherence of competence from childhood through adolescence. Child Development, 66, 1635-1659.

MedlinePlus. National Institute of Health, (2012). Alcoholism. Bethesda: U.S. National Library of Medicine.

Mensah, F. K., \& Kiernan, K. E. (2010). Parents' mental health and children's cognitive and social development. Social Psychiatry and Epidemiology, 45, 1023-1035.

Middelton-Moz, J., \& Dwinell, L. (2010). After the tears: Helping adult children of alcoholics heal their childhood trauma. Deerfield Beach, FL: Health Communications, Inc.

Molina, B. S., Donovan, J. E., \& Belendiuk, K. A. (2010). Familial loading for alcoholism and offspring behavior: Mediating and moderating influences. Alcoholism: Clinical and Experimental Research, 34, 1972-1984. 
Molitor, A., Mayes, L. C., \& Ward, A. (2003). Emotional regulation behavior during a separation procedure in 18-month-old children of mothers using cocaine and other drugs. Development and Psychopathology, 15, 39-54.

Neuendorf, K. A. (2002). The content analysis guidebook. Thousand Oaks, CA: Sage Publications.

National Institute on Alcohol Abuse and Alcoholism. (2010). Parenting to prevent childhood alcohol use. NIH Publication No. 10-7467.

Obot, I. S., \& Anthony, J. C. (2004). Mental health problems in adolescent children of alcohol dependent parents: Epidemiologic research with a nationally representative sample. Journal of Child \& Adolescent Substance Abuse, 13, 83-96.

Osterndorf, C. L., Enright, R. D., Holter, A. C., \& Klatt, J. S. (2011). Treating adult children of alcoholics through forgiveness therapy. Alcoholism Treatment Quarterly, 29, 274-292.

Pagano, M. E., Rende, R., Rodriguez, B. F., Hargraves, E. L., Moskowitz, A. T., \& Keller, M. B. (2007). Impact of parental history of substance use disorders on the clinical course of anxiety disorders. Substance Abuse Treatment, Prevention, and Policy, 2, ArtID 13. doi: $10.1186 / 1747-597 X-2-13$

Pender, N. J. (1996). Health promotion in nursing practice (3rd Ed.). Stamford, CT: Appleton \& Lange.

Pennebaker, J. W. (1990). Opening up: The healing power of confiding in others. New York: Avon Books.

Pennebaker, J. W., Kiecolt-Glaser, J. K., \& Glaser, R. (1988). Disclosure of traumas and immune function: Health implications for psychotherapy. Journal of Consulting and Clinical Psychology, 56, 239-245. 
Peterson, G. W., \& Hann, D. (1999). Socializing children and parents in families. In M. B. Sussman, S. K. Steinmetz, \& G. W. Peterson (Eds.), Handbook of Marriage and the Family (2nd ed., pp. 327-370). New York: Plenum.

Petronio, S. (2002). Boundaries of privacy: Dialectics of disclosure. Albany: State University of New York Press.

Quigley, B. M., \& Leonard, K. E. (2000). Alcohol, drugs, and violence. In V. B. Van Hasselt, \& M. Hersen (Eds.), Aggression and violence: An introductory text (pp. 259-283). Needham Heights, MA: Allyn \& Bacon.

Rangarajan, S., \& Kelly, L. (2006). Family communication patterns, family environment, and the impact of parental alcoholism on offspring self-esteem. Journal of Social and Personal Relationships, 23, 655-671.

Reich, W., Earls, F., \& Powell, J. (1988). A comparison of the home and social environments of children of alcoholic and non-alcoholic parents. British Journal of Addiction, 83, 831839.

Richards, S. T. \& Nelson, C. L. (2012). Problematic parental drinking and health: Investigating differences in adult children of alcoholics status, health locus of control, and health selfefficacy. Journal of Communication in Healthcare, 5, 84-90.

Rodriguez, E., Lasch, K. E., Chandra, J., \& Lee, P. (2001). Family violence, employment status, welfare benefits, and alcohol drinking in the United States: What is the relation? Journal of Epidemiology \& Community Health, 55, 172-178.

Roebuck, T. M., Mattson, S., \& Riley, E. P. (1999). Behavioral and psychosocial profiles of alcohol-exposed children. Alcoholism: Clinical and Experimental Research, 22, 279-294. 
Room, R., \& Greenfield, T. (1993). Alcoholics anonymous, other 12-step movements and psychotherapy in the US population. Addiction, $88,555-562$.

Ryan, W. P. (1991). Treatment issues with adult children of alcoholics. Psychoanalytic Psychology, 8, 69-82.

Schade, J. (2006). The complete encyclopedia of medicine and health. (pp. 132-133). Foreign Media Books.

Sloan, D. M., Marx, B. P., \& Epstein, E. M. (2005). Further examination of the exposure model underlying the efficacy of written emotional disclosure. Journal of Consulting and Clinical Psychology, 73, 549-554.

Slote, M. A. (2007). The ethics of care and empathy. New York: Routledge.

Slutske, W. S., D'Onofrio, B. M., Turkheimer, E., Emery, R. E., Harden, K. P., Heath, A. C., \& Martin, N. G. (2008). Searching for an environmental effect of parental alcoholism on offspring alcohol use disorder: A genetically informed study of children of alcoholics. Journal of Abnormal Psychology, 117, 534-551.

Strauss, M. A., \& Corbin, J. (1990). Basics of qualitative research: Grounded theory procedures and techniques. Newbury Park, CA: Sage.

Strauss, M. A., \& Sweet, S. (1992). Verbal/symbolic aggression in couples: Incidence rates and relationships to personal characteristics. Journal of Marriage \& the Family, 54, 346-357.

Sullivan, R. J. (1995). An introduction to Kant's ethics. Cambridge, UK: Cambridge University Press.

Testa, M., Quigley, B. M., \& Leonard, K. E. (2003). Does alcohol make a difference? Withinparticipants comparison of incidents of partner violence. Journal of Interpersonal Violence, 18, 735-743. 
Tidwell, L. C., \& Walther, J. B. (2002). Computer-mediated communication effects on disclosure, impressions, and interpersonal evaluations: Getting to know one another a bit at a time. Human Communication Research, 28, 317-348.

Vernig, P. M. (2011). Family roles in homes with alcohol-dependent parents: An evidence based review. Substance Use \& Misuse, 46, 535-542.

Walker, J. P., \& Lee, R. E. (1998). Uncovering strengths of children of alcoholic parents. Contemporary Family Therapy, 20, 521-538.

Waller, B. N. (2005). Consider ethics: Theory, readings, and contemporary issues. New York: Pearson Longman.

Walther, J. B., \& Boyd, S. (2002). Attraction to computer-mediated social support. In C. A. Lin \& D. Atkin (Eds.), Communication technology and society: Audience adoption and uses (pp. 153-188). Cresskill, NJ: Hampton Press.

Walther, J. B., \& Burgoon, J. K. (1992). Relational communication in computer-mediated interaction. Human Communication Research, 19, 50-88.

Wekerle, C., \& Wall, A. (2002). The violence and addiction equation: Theoretical and clinical issues in substance abuse and relationship violence. New York: Brunner-Routledge.

Woititz, J. G. (1985). Struggle for intimacy. Deerfield Beach, FL: Health Communications, Inc. 


\section{Endnotes}

1 Each message board community exists for families affected by alcoholism. The Sober Recovery website offers a variety of forums for members to choose from including: newcomer forum, gratitude list, secular recovery, and friends and family of alcoholics. Each forum has a moderator and anonymity of members is a primary policy of the community. Cyber Recovery Social Network Forums emphasizes a 12-step program format and highlights a variety of forums for individuals including: family and friends of alcoholics/addicts, adult children of alcoholics, and co-dependents anonymous. Miracles in Progress-12-Step Forum also subscribes to a 12-step support program with a variety of forums to choose from depending on member interest. Forums include alcoholics anonymous, al-anon family group, and ACoA message board.

2 Holidays like Christmas, Hanukah, and New Years fell during our data collection window. Although it is possible that increased family interaction during the holidays may make the issue more salient, this does not appear to have altered our results. Notably, data was collected from the beginning of December to the end of January so the holiday season was a small period during that timeframe. A review of the data revealed that all of the themes were relevant throughout the course of data collection, none of them only appeared to emerge during the holidays. 